\title{
Comparative study between intrathecal Nalbuphine and Fentanyl as an adjuvant to hyperbaric Bupivacaine in transabdominal hysterectomy
}

\author{
Chethanananda $\mathrm{T} \mathrm{N}^{1}$, Annamreddy Anantha Rao ${ }^{2 *}$, Suhana Banu ${ }^{3}$, Ranjitha $\mathrm{C}^{4}$ \\ ${ }^{1}$ Professor, ${ }^{3,4}$ Post graduates, Department of Anaesthesiology, Adichunchanagiri Institute of Medical Sciences, Adichunchanagiri University, \\ B G Nagara 571448, Mandya Dist, Karnataka, INDIA. \\ 2Senior Specialist, Vizag Steel General Hospital, RINL, Ukkunagaram, Sector 6, Visakhapatnam 530032, Andhrapradesh, INDIA. \\ Email: ranjithachandru1@gmail.com
}

\section{$\underline{\text { Abstract }}$}

\begin{abstract}
Background: The study was to compare the sensory and motor blockade characteristics and duration of postoperative analgesia between Nalbuphine and Fentanyl as an adjunct to intrathecal Bupivacaine in spinal anaesthesia. Settings and design: To compare the clinical efficacy of hyperbaric Bupivacaine with Fentanyl and hyperbaric Bupivacaine with Nalbuphine with reference to onset and duration of sensory block, onset and duration of motor block, duration of post op analgesia, hemodynamic stability, level of sedation and complications. Methodology: 60 female patients of 30-55 years of age with ASA I, II undergoing elective trans-abdominal hysterectomy under spinal anaesthesia were randomly allocated to two groups. Group BUF - $0.5 \mathrm{ml}(25 \mu \mathrm{g})$ Fentanyl and Group BUN - $0.5 \mathrm{ml}(1 \mathrm{mg})$ Nalbuphine, with $3 \mathrm{ml}$ of $0.5 \%$ hyperbaric Bupivacaine. Onset and duration of sensory block, duration of post op analgesia, hemodynamic stability, level of sedation and complications were assessed. Statistical analysis: Data were analysed using Student $t$ test and Chi-square test for parameters on continuous scale and categorical scale respectively $\mathrm{p}$ value $<0.05$ was considered significant. Results: Though onset of sensory and motor block was faster in BUF, the BUN group had prolonged post op analgesia. Mean VAPS reduction at $24 \mathrm{hr}$ in BUN (3.26+/- 0.541) compared to BUF $(2.78+/-0.585)$ was statistically significant with $p$ value $0.0016(<0.05)$. No statistical significance was seen with respect to hemodynamic stability and duration of motor block. Conclusion: Nalbuphine, an agonist-antagonist is a good adjuvant to intrathecal Bupivacaine, providing intense and prolonged postoperative analgesia without any significant adverse effects.
\end{abstract}

Key Words: Spinal anaesthesia, Bupivacaine, Nalbuphine, Fentanyl, Postop analgesia.

\section{*Address for Correspondence:}

Dr Annamreddy Anantha Rao, Senior Specialist, Vizag Steel General Hospital, RINL, Ukkunagaram, Sector 6, Visakhapatnam 530032, Andhrapradesh, INDIA.

Email: ranjithachandru1@gmail.com

Received Date: 04/04/2020 Revised Date: 12/05/2020 Accepted Date: 01/06/2020

DOI: https://doi.org/10.26611/10151522

This work is licensed under a Creative Commons Attribution-NonCommercial 4.0 International License. (cc)) EY-NC

\begin{tabular}{|l|l|}
\hline \multicolumn{2}{|c|}{ Access this article online } \\
\hline Quick Response Code: & Website: \\
\cline { 1 - 2 } & www.medpulse.in \\
& \\
& \\
\end{tabular}

\section{INTRODUCTION}

Spinal anaesthesia has many potential advantages over general anaesthesia, especially for operations involving the lower abdomen, the perineum and the lower extremities. ${ }^{1}$ Spinal anaesthesia with hyperbaric Bupivacaine $0.5 \%$ is popular method for longer procedures due to its prolonged duration. Addition of intrathecal opioids is needed to intensify and enhance the duration of sensory blockade and post-operative analgesia without increasing the sympathetic block ${ }^{2}$. Local anaesthetics work by inhibiting voltage-gated sodium channels in the spinal cord by interfering with afferent and efferent sensory and motor impulses while intrathecal opioids activate opioid receptors 
in the dorsal grey matter of the spinal cord (substantia gelatinosa) to modulate the function of afferent pain fibers. ${ }^{3}$ This study is designed to quantitatively examine the effects of adding Nalbuphine and Fentanyl to hyperbaric Bupivacaine hydrochloride in spinal anaesthesia, to evaluate the efficacy, to know the duration of postoperative analgesia and to know the complications if any. Highly hydrophilic opioids such as Morphine, though provides very good intra and post-operative analgesia, its use becomes limited because of delayed respiratory depression that it causes due to rostral spread in intrathecal space. ${ }^{4}$ Fentanyl is a potent synthetic opioid agonist and Nalbuphine is a synthetic opioid agonist-antagonist analgesic. ${ }^{5}$

\section{MATERIALS AND METHODS}

A single blinded randomised prospective study was conducted after obtaining clearance from Institutional ethical committee. Written informed consent was taken from sixty patients who were included in the study at Adichunchanagiri Institute of Medical Sciences, Mandya District. 60 patients of 30-55 years of age with ASA I, II undergoing elective trans-abdominal hysterectomy under spinal anaesthesia, were randomly allocated to two groups by computer-generated table of random numbers. Group BUF $(n=30)$ - Inj. hyperbaric Bupivacaine $0.5 \%$ of $3 \mathrm{ml}$ $(15 \mathrm{mg})$, Fentanyl $0.5 \mathrm{ml}(25 \mu \mathrm{g})$ intrathecally. Group BUN $(\mathrm{n}=30)$-Inj hyperbaric Bupivacaine $0.5 \%$ of $3 \mathrm{ml}(15 \mathrm{mg})$ plus Nalbuphine $0.5 \mathrm{ml}(1 \mathrm{mg})$ intrathecally. Patients who have not given consent, with medical disorders, coagulation abnormalities and those with local skin infection were excluded from the study. A detailed pre-anaesthetic evaluation and relevant laboratory and radiological investigations was undertaken. All patients received tablet Ranitidine $150 \mathrm{mg}$ and tablet Alprazolam $0.5 \mathrm{mg}$ as premedication in the night and were advised nil per orally from 12 midnight prior to the day of surgery. On the day of surgery, all the resuscitation equipments, E.T tubes, anaesthesia machine, emergency drugs were kept ready. Patients were preloaded with Ringer lactate solution at the rate of $15 \mathrm{ml} / \mathrm{kg}$ via $18 \mathrm{G} \mathrm{IV}$ cannula. Monitors connected [continuous electrocardiogram (ECG), $\mathrm{SpO}$, noninvasive blood pressure (NIBP)], respiratory rate and baseline readings were noted. Under strict aseptic precautions, mid line lumbar puncture was done at L3- L4 interspace using $26 \mathrm{G}$ spinal needle with patient in lateral position. The study drug was injected into the subarachnoid space after noting the clear free flow of CSF at the rate of $0.2 \mathrm{ml} /$ second. Patients were turned supine immediately. The pulse rate, systolic BP, diastolic BP, SPO2 and respiratory rate were recorded every $2 \mathrm{~min}$ for 5 minutes, and every $5 \mathrm{~min}$ for 30 minutes and every $15 \mathrm{~min}$ there after till $60 \mathrm{~min}$, then every
30 min till 150 min. A fall of systolic blood pressure $>30 \mathrm{mmHg}$ from the baseline or MAP $<60 \mathrm{mmHg}$ reading was taken as hypotension and was treated with intravenous fluids and incremental dose of Inj. Ephedrine $6 \mathrm{mg}$. Bradycardia defined as heart rate $<60$ beats per min and treated with IV atropine $0.6 \mathrm{mg}$. Respiratory depression defined as respiratory rate less than $8 / \mathrm{min}$ (or) SPO $2<85 \%$ and oxygen supplementation was given through face mask for such cases. Onset of sensory block was taken as time from intrathecal injection to loss of pin prick sensation at T10 level. Motor block was assessed using the modified Bromage score. Time for two- segment regression from the highest sensory level and time for rescue analgesia was the time taken in minutes from the time of injection to the time when the patient complained of pain at surgical site with VAPS of $>4$ and was treated with suitable analgesics. Duration of motor block was till the patient attained complete motor recovery of lower limb. Sedation was assessed by Ramsay sedation scale. Side effect like nausea, vomiting, hypotension, respiratory depression, pruritus, shivering, allergic reactions were noted and managed if necessary.

Statistical analysis

Data were analyzed using software version SPSS-20 (IBM SPSS statistics for windows, version 20.0. Armonk, NY, USA). Student $t$ test for parameters on continuous scale. Chi-square test for parameters on categorical scale. Standard tests of significance were applied to determine " $p$ " value, $p<0.05$ was considered statistically significant. Trend graphs and bar graphs were drawn accordingly.

\section{RESULTS}

Demographic profile

The groups were comparable with respect to the demographic profile.

Table 1: Comparison of Mean VAPS reduction at 24hr between groups

\begin{tabular}{lccc}
\hline GROUP & Mean & $\begin{array}{c}\text { Standard } \\
\text { deviation }\end{array}$ & P value \\
\hline BUF & 2.78 & 0.585 & 0.0016 \\
BUN & 3.26 & 0.541 & \\
\hline
\end{tabular}

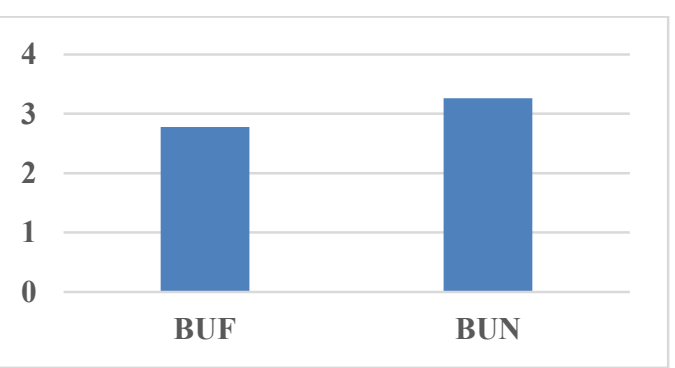

Figure 1: Mean VAPS reduction at 24hr 
Table 2: Comparison of Onset time of Sensory Blockade between

\begin{tabular}{llcl}
\multicolumn{4}{c}{ groups } \\
\hline GROUP & $\begin{array}{c}\text { Mean } \\
\text { (in min) }\end{array}$ & $\begin{array}{c}\text { Standard } \\
\text { deviation }\end{array}$ & P value \\
\hline BUF & 3.03 & 0.49 & 0.004 \\
BUN & 3.50 & 3.03 & \\
\hline
\end{tabular}

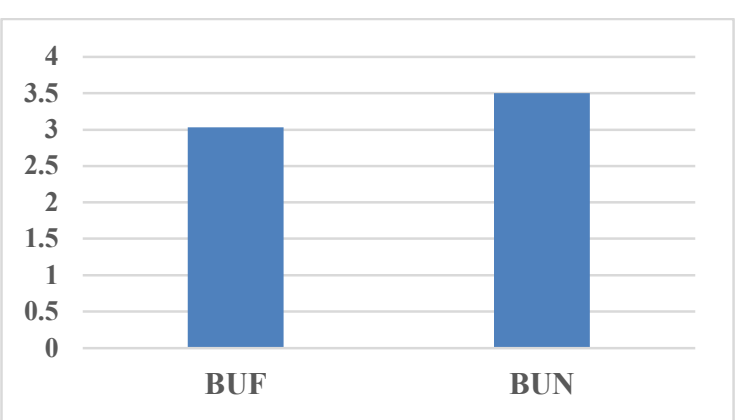

Figure 2: Onset of sensory blockade

Table 3: Comparison of Onset of Motor Blockade between groups

\begin{tabular}{cclc}
\hline GROUP & $\begin{array}{c}\text { Mean } \\
\text { (in min) }\end{array}$ & $\begin{array}{c}\text { Standard } \\
\text { deviation }\end{array}$ & P value \\
\hline BUF & 3.83 & 1.13 & $<0.001$ \\
BUN & 4.76 & 0.986 & \\
\hline
\end{tabular}

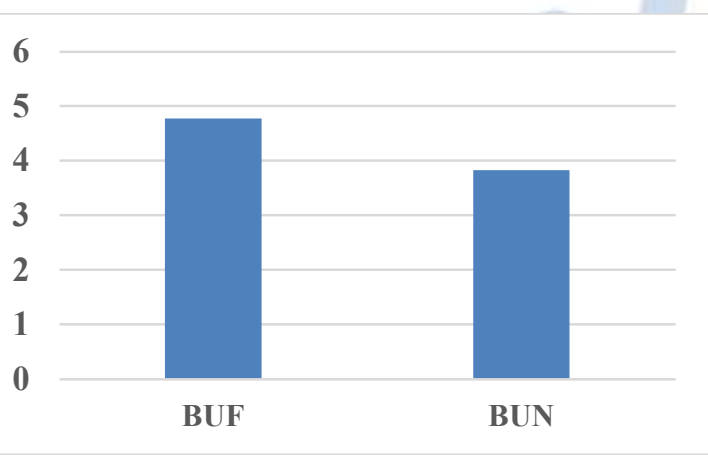

Figure 3: Onset of Motor blockade

Table 4: Comparison of Mean duration of two segment regression of sensory level between groups

\begin{tabular}{cccc}
\hline GROUP & $\begin{array}{c}\text { Mean } \\
\text { (in min) }\end{array}$ & $\begin{array}{c}\text { Standard } \\
\text { deviation }\end{array}$ & P value \\
\hline BUF & 87.6 & 3.9 & $<0.001$ \\
BUN & 95.3 & 5.07 & \\
\hline
\end{tabular}

Table 5: Comparison of Mean duration of motor block between groups

\begin{tabular}{cccc}
\hline GROUP & Mean (in min) & Standard deviation & P value \\
\hline BUF & 143.87 & 4.2 & 0.76 \\
BUN & 140.73 & 11.7 & \\
\hline
\end{tabular}

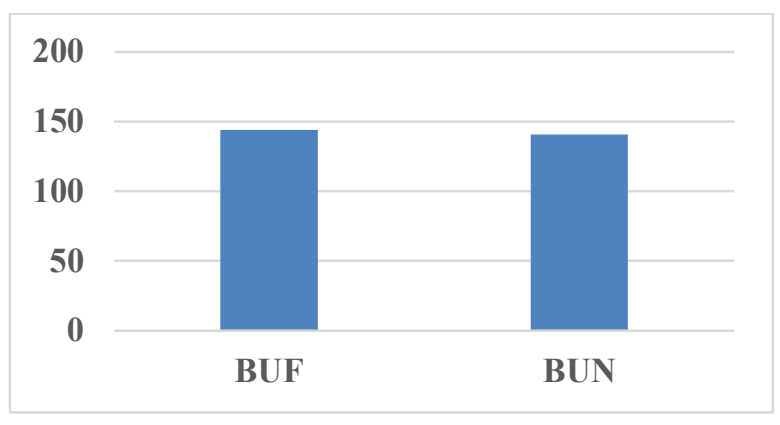

Table 6: Comparison of Mean duration of rescue analgesic requirement between groups

\begin{tabular}{ccll}
\hline GROUP & $\begin{array}{c}\text { Mean } \\
\text { (in min) }\end{array}$ & $\begin{array}{l}\text { Standard } \\
\text { deviation }\end{array}$ & P value \\
\hline BUF & 285.97 & 8.8 & $<0.001$ \\
BUN & 430.3 & 11.13 & \\
\hline
\end{tabular}

Table 7: Distribution of subjects according to side effects between

\begin{tabular}{cccc}
\multicolumn{4}{c}{ the groups } \\
\cline { 2 - 4 } Side Effect & \multicolumn{3}{c}{ Group } \\
\cline { 2 - 4 } Nil & 21 & BUN & Total \\
\hline \multirow{2}{*}{ Bradycardia } & $70.0 \%$ & $80.0 \%$ & $75.0 \%$ \\
& 1 & 1 & 2 \\
Hypotension & $3.3 \%$ & $3.3 \%$ & $3.3 \%$ \\
& 2 & 1 & 3 \\
Nausea & $6.7 \%$ & $3.3 \%$ & $5.0 \%$ \\
& 2 & 2 & 4 \\
Shivering & $6.7 \%$ & $6.7 \%$ & $6.7 \%$ \\
& 3 & 1 & 4 \\
Vomiting & $10.0 \%$ & $3.3 \%$ & $6.7 \%$ \\
& 1 & 1 & 2 \\
& $3.3 \%$ & $3.3 \%$ & $3.3 \%$ \\
\hline Total & 30 & 30 & 60 \\
& $100.0 \%$ & $100.0 \%$ & $100.0 \%$ \\
\hline
\end{tabular}

There was no statistically significant difference found between side effects and groups

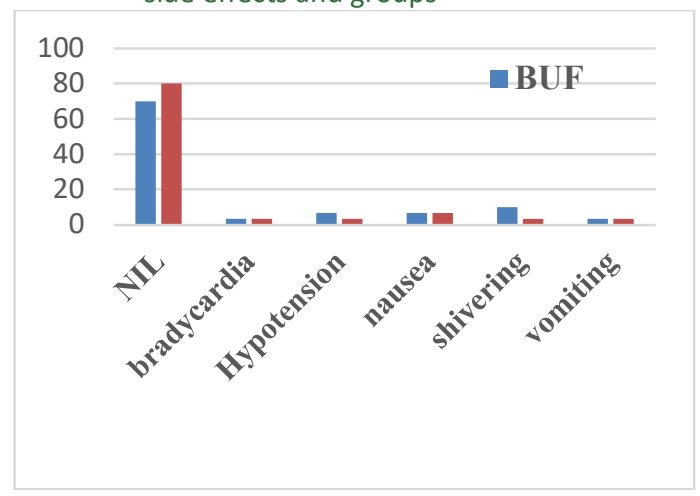




\section{RESULTS}

Though onset of sensory and motor block was faster in Fentanyl group, the Nalbuphine group had prolonged post op analgesia. Mean VAPS reduction at $24 \mathrm{hr}$ in Nalbuphine (3.26+/- 0.541) compared to Fentanyl $(2.78+/-0.585)$ was statistically significant with $\mathrm{p}$ value $0.0016(<0.05)$. Both groups showed no significant differences with respect to demographic profile and hemodynamic parameters.

\section{DISCUSSION}

Opioid analogues as adjuvants to intrathecal Bupivacaine enhances the onset of sensory and motor block, provides postoperative analgesia and prolongs the duration of block. Fentanyl acts by binding with opioid receptors in the dorsal horn of spinal cord and may also have its action via supraspinal spread when given intrathecally and has been used as an adjuvant to local anesthetics in subarachnoid block, and reduces both visceral and somatic pain ${ }^{6}$. Harbhej singh et al. ${ }^{7}$ in 1995, BN Biswas et al.. ${ }^{8}$ in 2002, Khanna MS et al. ${ }^{9}$ in 2002 had chosen 25 micrograms of Fentanyl as an additive to intrathecal hyperbaric Bupivacaine in their studies. Hence in our study, we chose 25 micrograms of Fentanyl as an additive to hyperbaric Bupivacaine.

Nalbuphine ${ }^{10,11}$ is a synthetic lipophilic opioid with agonist action at the kappa opioid receptor and antagonist at the mu receptor. It inhibits release of neurotransmitter that mediates pain such as substance P. In addition it acts as post synaptic inhibitor on the interneuron and output neuron of spinothalamic tract which transports nociceptive information. It improves quality of block and offers prolonged and long lasting postoperative analgesia. It has low incidence of adverse effects known for other opioids (respiratory depression, nausea, vomiting, pruritis). Onset of sensory and motor block was faster in Fentanyl group as compared to Nalbuphine group as in a study conducted by Shagufta et al. ${ }^{12}$ and Bisth s et al. ${ }^{13}$ Two segment regression was more prolonged with Nalbuphine group compared with Fentanyl which was consistent with that of a study by Gomaa et al. ${ }^{2}$ There was no significant difference among two groups in duration of motor block with $p$ value ( $p>0.05$ ) supported by the study conducted by Gupta et al. ${ }^{3}$ In a study conducted by Gupta et al. ${ }^{3}$ and Culebras et al. ${ }^{14}$, Nalbuphine prolonged the duration of post-operative analgesia. Requirement of Rescue analgesics and Visual analogue scores were significantly low in Nalbuphine than Fentanyl, similar to the study done by Tiwari and Tomar ${ }^{15}$ As far as side effects of intrathecal opioids were concerned in our study, patients in both groups had minimal side effects. No pruritus, respiratory depression, euphoria, dysphoria, desaturation was observed in both the groups.

\section{CONCLUSION}

Intrathecal Nalbuphine is a good adjuvant to Bupivacaine, providing intense and prolonged postoperative analgesia without any significant adverse effects. Being an agonistantagonist, it is devoid of the usual opioid side effects. Unlike Fentanyl, it is not included under the Narcotic Act, hence it is easily available in the pharmacy on prescription.

\section{REFERENCES}

1. Christopher M. Bernards: Epidural and spinal anaesthesia in: Paul G. Barash Clinical anaesthesia $6^{\text {th }}$ edition Wolster Kluwer Lippioncot Williams and Wilkins New York 2010:927-950.

2. Hala Mostafa Gomaa, Nashwa Nabil Mohamedet al... A comparison between post-operative analgesia after intrathecalnal buphine with bupivicaine and intrathecal fentanyl with bupivicaine after cesarean section. In: Egyptian journal of Anaesthesia. Elsevier. 2014:05:410.

3. Gupta K, Rastogi B, Gupta PK, Singh I, Bansal M, Tyagi V. Intrathecal nalbuphine versus intrathecal fentanyl as adjuvant to $0.5 \%$ hyperbaric bupivacaine for orthopedic surgery of lower limbs under subarachnoid block: A comparative evaluation. Indian J Pain 2016;30:90-5

4. Biswas BN, Rudra A, Bose BK, Nath S, Chakrabarty S, Bhattacharjee S. Intrathecal fentanyl with hyperbaric bupivacaine improves analgesia during caesarean delivery and in early post operative period. Indian J. Anaesth. 2002; 46(6): 469-472.

5. National Journal of Medical and Dental Research, JanuaryMarch 2016: Volume-4, Issue-2, Page 93-100.

6. Robert K Stoelting. Opioid agonists and antagonists. In Pharmacology and Physiology in anesthetic practice. Ed by Robert K Stoelting, Simon C Hillier. 4thedn. Lippincott Williams and wilkins. 1999; 87-122.

7. Singh H, Yang J, Thornton K, Giesecke AH. Intrathecal fentanyl prolongs sensory bupivacaine spinal block. Can J Anaesth. 1995; 42(11): 987-991.

8. Biswas BN, Rudra A, Saha JK, Karmakar S. Comparative study between effects of intrathecal midazolam and fentanyl on early postoperative pain relief after inguinal herniorrhaphy. J Anaesth. Clin. Pharmacol. 2002; 18(3): 280-283.

9. Khanna MS, Singh IKJP. Comparative evaluation of bupivacaine plain versus bupivacaine with fentanyl in spinal anaesthesia in geriatric patients. Indian J. Anaesth. 2002; 46(3): 199-203.

10. Stoelting RK, Hiller SC. Opioid agonists and antagonists.In; Pharmacology and physiology in anesthetic practice, $4^{\text {th }}$ edition, Philadelphia;Lippincortt Williams and Wilkins;2006:87-122

11. Dollery C Therapeutic drugs $2^{\text {nd }}$ edition. London; Churchill livingstone;1999:N14-N17.

12. Shagufta Naaz1, Usha Shukla2, Swati Srivastava3, Erum Ozair4 , Adil Asghar5. A Comparative Study of Analgesic Effect of Intrathecal Nalbuphine and Fentanyl as Adjuvant in Lower Limb Orthopaedic Surgery. Journal of Clinical and Diagnostic Research. 2017 Jul, Vol-11(7): UC25UC28

13. Bisht S, Rashmi D. Comparison of intrathecal fentanyl and nalbuphine: A prospective randomized controlled study in patients undergoing total abdominal hysterectomy. Anaesth Pain and Intensive Care 2017;21(2):194-198 
14. Culebras X, Gaggero G, Zatloucal J, Kern C, Marti RA, Advantages of Inrathecal Nalbuphine, compared with Intrathecal Morphine, After caesarean delivery: An evaluation of post operative Analgesia and Adverse effects. Anesth Analg 2000; 91: 601-5.
15. Tiwari AK, Tomar GS et al... Intrathecal bupivicaine in comparison with combination of nalbuphine and bupivicaine for subarachnoid block: A randomised prospective double blind clinical study. In: Am J Ther. 2013;6:592-5.

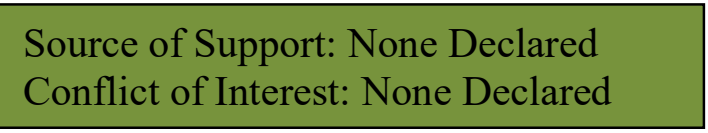

\section{Policy for Articles with Open Access:}

Authors who publish with MedPulse International Journal of Anesthesiology (Print ISSN:2579-0900) (Online ISSN: 2636-4654) agree to the following terms: Authors retain copyright and grant the journal right of first publication with the work simultaneously licensed under a Creative Commons Attribution License that allows others to share the work with an acknowledgement of the work's authorship and initial publication in this journal.

Authors are permitted and encouraged to post links to their work online (e.g., in institutional repositories or on their website) prior to and during the submission process, as it can lead to productive exchanges, as well as earlier and greater citation of published work. 